\section{Curschmann, Heinrich}

\author{
A. M. Gressner ${ }^{1}$ und O. A. Gressner ${ }^{2}$ \\ ${ }^{1}$ Labor Dr. Wisplinghoff Berlin, Berlin, Deutschland \\ ${ }^{2}$ Labor Dr. Wisplinghoff Köln, Köln, Deutschland
}

Lebensdaten Deutscher Mediziner, geboren am 28. Juni 1846 in Gießen, gestorben am 6. Mai 1910 in Leipzig.
Verdienste Professor für Innere Medizin in Hamburg und Leipzig, hat zahlreiche und neue Beobachtungen über Infektionskrankheiten (Pocken, Fleckfieber, Typhus) und über Bronchialasthma, Abdominaltyphus, Blattern etc. beschrieben. Wurde besonders bekannt durch seine Entdeckung der - Curschmann-Spiralen im Sputum bei Bronchialasthma. 